\title{
Fatigue behaviour of bridge deck slab elements strengthened with reinforced UHPFRC
}

\author{
T. Makita \& E. Brühwiler \\ Laboratory of Maintenance and Safety of Structures (MCS), École Polytechnique Fédérale de Lausanne \\ (EPFL), Lausanne, Switzerland
}

\begin{abstract}
With the occurrence of higher and more frequent axle loads on roads, in particular bridge deck slabs are more severely solicitated by fatigue loading. To avoid heavy interventions for strengthening of bridge deck slabs, an improved building material is used, namely Ultra-High Performance Fibre Reinforced Concrete containing steel rebars (=R-UHPFRC). By adding a thin (30 to $50 \mathrm{~mm}$ ) layer of R-UHPFRC on top of the deck slab, the required fatigue resistance and load carrying capacity may be restored and improved. In addition the R-UHPFRC layer is waterproof which provides improved durability. This paper presents results of fatigue tests for the determination of the fatigue behaviour of reinforced concrete (RC) slab-like beams strengthened with R-UHPFRC leading to RU-RC beams. The experimental results show high fatigue resistance of RU-RC beams indicating a significant potential for strengthening of RC bridge deck slabs. For the application, rules are deduced for the design of the RU-RC member and the corresponding fatigue safety verification. Finally, an application of this novel technology is briefly described demonstrating that improvement of bridge deck slabs using UHPFRC is a relatively gentle intervention with limited intervention costs. There is a potential inherent with this novel construction method to limit the duration of the working site and thus to reduce the user costs as well as life cycle costs.
\end{abstract}

\section{INTRODUCTION}

The development of economic activity has accelerated the increase of traffic volume since the late 20th century. In order to keep up with this increase, transportation infrastructures are required to improve their traffic and load bearing capacities. As for the improvement of load bearing capacity, it is usually carried out by exchanging existing structural members or adding new structural members. If one operation of such maintenance works is the only intervention during the service life, it is desirable in terms of life cycle maintenance strategy to follow Strategy A according to Figure 1 implying enhanced durability. In this context, the concept of application of UltraHigh Performance Fibre Reinforced Concrete reinforced with steel rebars (R-UHPFRC) to improve existing concrete members was conceived. UHPFRC has eminent properties such as relatively high compressive and tensile strength, low permeability, strain-hardening behaviour in tension.

The objectives of the present paper are to describe the bending fatigue behaviour of R-UHPFRC reinforced concrete composite member (RU-RC member) and demonstrate the effectiveness of fatigue strengthening of existing RC bridge deck slabs using R-UHPFRC. The experimental set-up represe-

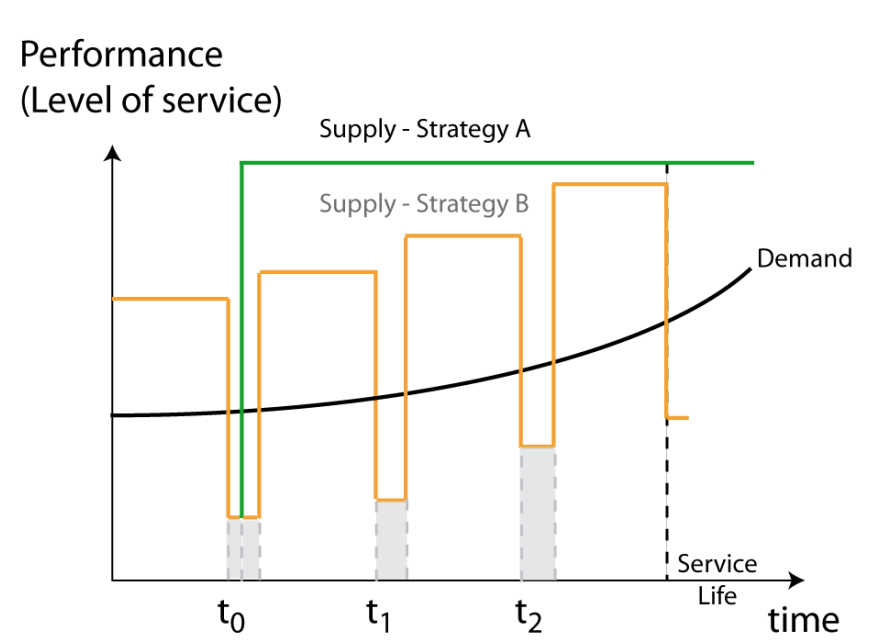

Figure 1. Life cycle maintenance strategies (Denarié \& Brühwiler)

nts a strip of RC bridge deck cantilever strengthened with R-UHPFRC (circled part in Figure 2). The experimental tests are detailed and the test results are analysed. Design rules for the RU-RC member and the corresponding fatigue safety verification are then proposed. In the final part of the present paper, an on-site application of R-UHPFRC layer to RC bridge deck slab is described. 


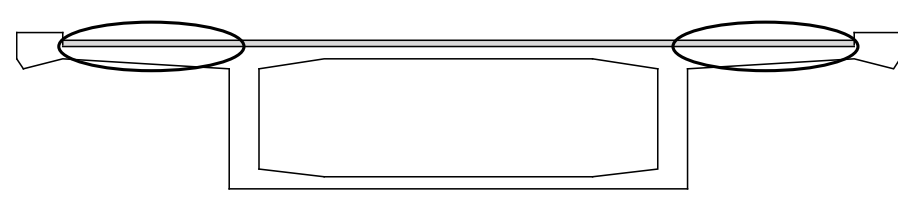

Figure 2. RC bridge slab improved with R-UHPFRC layer

\section{BEHAVIOUR OF UHPFRC UNDER QUASI- STATIC TENSION}

The tensile behaviour of UHPFRC is characterised by three domains as observed in quasi-static tensile tests:

- The elastic domain is governed by the behaviour of the matrix until it reaches its tensile strength, called the elastic limit strength. Microcracks start to form at this stress level.

- These microcracks are bridged and controlled by fibres. After entering into the strain-hardening domain, more microcracks develop in the whole specimen volume. A considerable reduction in modulus of deformation, i.e. the ratio of stress to strain, is observed. The strain-hardening extends until the ultimate resistance or tensile strength is reached in the weakest section of the specimen.

- In the strain-softening domain beyond ultimate resistance, a discrete macrocrack forms in this weakest section and becomes eventually visible. Consequently, deformation localizes in the macrocrack zone while the zones outside are unloaded. Finally the specimen fails in two parts at the end of softening.

In the present paper microcrack is defined as a crack which is not visible to the naked eye and its width is commonly much smaller than $0.05 \mathrm{~mm}$. Macrocrack is defined as a crack which is visible to the naked eye and its width is larger than $0.05 \mathrm{~mm}$.

\section{EXPERIMENTAL TESTS}

\subsection{Specimens, test set-up and instrumentation}

The specimen is a $1900 \mathrm{~mm}$ long slab-like beam with a cross section of $400 \mathrm{~mm} \times 220 \mathrm{~mm}$ (Fig. 3). Thickness of R-UHPFRC layer is $50 \mathrm{~mm}$ using an in-house developed UHPFRC mix called HIFCOM 13. This mix is characterised by 3.0 vol.- $\%$ content of steel fibres $13 \mathrm{~mm}$ long with a diameter of 0.16 $\mathrm{mm}$ and by the use of CEM III/B type cement which contains a high percentage of blast furnace slag $(66 \% \sim 80 \%)$. Although the static strength of UHPFRC in tension depends on casting procedure and element configuration (Wuest 2007), the average elastic limit strength and ultimate strength were determined from quasi-static uniaxial tensile tests using monolithic UHPFRC plates to be around $10 \mathrm{MPa}$ and $12 \mathrm{MPa}$ each. Four steel rebars of $8 \mathrm{~mm}$ diameter were arranged in the UHPFRC layer with a spacing of $100 \mathrm{~mm}$.

Concrete in the $\mathrm{RC}$ part was $\mathrm{C} 30 / 37$ grade with a maximum aggregate size of $16 \mathrm{~mm}$. The average tested concrete cylinder compressive strength was $64.5 \mathrm{MPa}$ after 180 days. Four steel rebars of $16 \mathrm{~mm}$ and $10 \mathrm{~mm}$ diameter were arranged in the top and bottom of the RC part with a spacing of $100 \mathrm{~mm}$.

All of steel rebars used in the experimental tests were of B500B grade and had a nominal yielding strength of $500 \mathrm{MPa}$.

The RC part was first cast, and 28 days later the UHPFRC layer was cast on the top surface of the $\mathrm{RC}$ part which was roughened with hydro-jetting to obtain monolithic bond between UHPFRC and concrete. (Neither any adhesion products nor any shear connector was used for the bonding.)

Linear Variable Differential Transducer (LVDT) was set to measure the specimen deflection at the position of the jack (Fig. 3). Seven displacement transducers with a base length of $100 \mathrm{~mm}$ were set at the transversal centre of the top surface of $\mathrm{R}$ UHPFRC layer to measure the R-UHPFRC deformation (Fig. 3). The displacement transducers were intended to cover the area where the largest negative bending moment acted.

Top view of the specimen

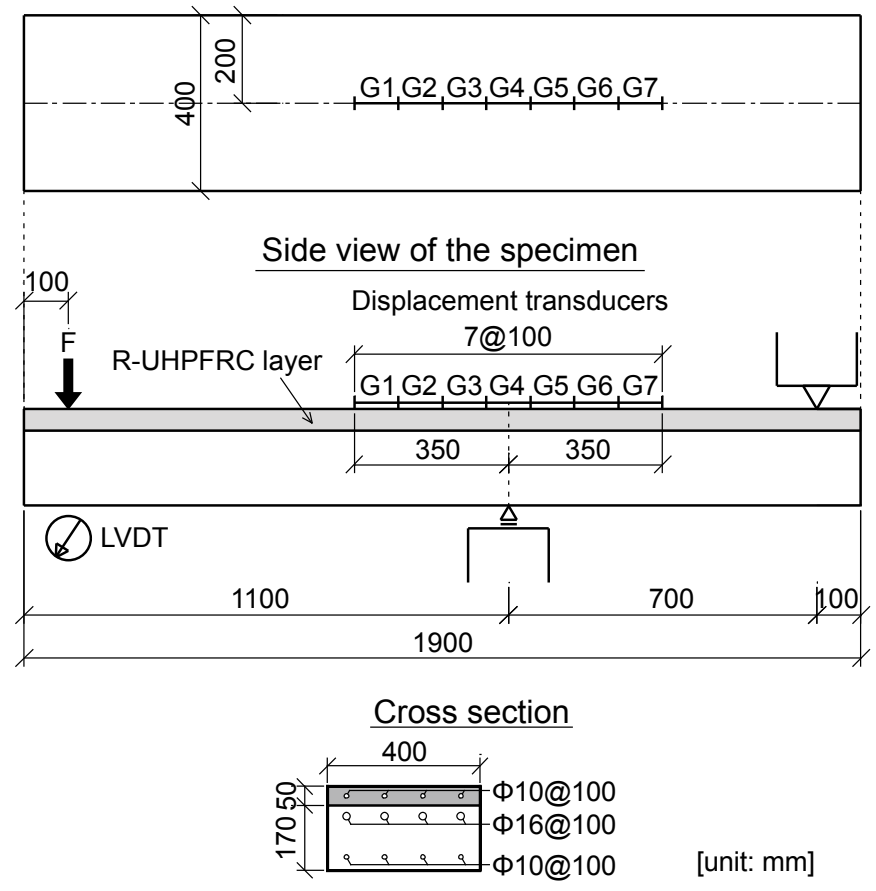

Figure 3. Specimen geometry, measuring devices and test setup 


\subsection{Testing program}

Maximum fatigue force $F_{\max }$ was varied between $40 \%$ and $60 \%$ of the ultimate static strength $F_{u}$ of the specimen. $\mathrm{F}_{\mathrm{u}}$ was determined to be $90 \mathrm{kN}$ from one static test with the same specimen type as used in the fatigue tests. Applied minimum fatigue force was always $10 \%$ of maximum force. When a specimen sustained more than 10 million fatigue cycles, the test was regarded as "run-out" and the new fatigue test was continued at a higher fatigue force level.

In the present paper the fatigue limit is defined as a normalised force (i.e. the ratio $\mathrm{S}=\mathrm{F}_{\max } / \mathrm{F}_{\mathrm{u}}$ ) below which no fatigue failure occurs after 10 million fatigue cycles. In fact, 10 million is not a large number of cycles when considering actual numbers of axle load cycles occurring on bridge deck slabs. However, as limited time is available for the experimental campaign, 10 million is considered as representative for estimation of the fatigue limit in the high cycle fatigue domain.

Fatigue force was applied manually during the first 10 cycles; then sinusoidal fatigue force cycles were imposed at $8 \mathrm{~Hz}$ using hydraulic actuator. Force was measured by the load cell installed just below the force applying jack.

Deflection, deformation and force data were recorded with a frequency of $160 \mathrm{~Hz}$. The initial and final phases of the tests were recorded permanently, while between these phases data was recorded for 1 second every 480 cycles.

\section{RESULTS AND DISCUSSION OF EXPERIMENTAL RESULTS}

\subsection{Fatigue limit}

Table 1 summarises the results of bending fatigue tests of RU-RC beams. When the whole testing system became unstable due to reduction of stiffness of the specimen and force could no longer be applied, the fatigue test was stopped and specimen was regarded as failed.

Figure 4 shows the S-N diagram as obtained in the present study from the RU-RC beam specimens. In order to eliminate variations in material composition, specimen size and testing set-up, normalised force $\mathrm{S}$ is used for vertical axis. Scatter in the results may be explained by differences in static strength and age of specimens. As material properties of UHPFRC depend on fibre distribution and orientation (Wuest 2007), this might have influenced the variety of the static strength of the RU-RC beam in the present case. The fatigue limit may be estimated to be at a level of $\mathrm{S}=0.5$ or $50 \%$ of $\mathrm{F}_{\mathrm{u}}$.
Table 1 Results of bending fatigue tests of RU-RC composite beam

\begin{tabular}{ccccccl}
\hline \multirow{2}{*}{ Test } & $\mathrm{F}_{\max }$ & $\mathrm{F}_{\min }$ & $\mathrm{S}$ & Cycles & Remarks \\
\cline { 2 - 5 } & $\mathrm{kN}$ & $\mathrm{kN}$ & $\%$ & $\times 10^{6}$ & \\
\hline \multirow{2}{*}{1} & i & 36.0 & 3.6 & 40 & 10.13 & run-out \\
& ii & 45.0 & 4.5 & 50 & 1.04 & \\
2 & i & 40.5 & 4.0 & 45 & 20.00 & run-out \\
& ii & 45.0 & 4.5 & 50 & 1.97 & \\
& i & 45.0 & 4.5 & 50 & 23.94 & run-out \\
3 & ii & 49.5 & 4.9 & 55 & 10.00 & run-out \\
& iii & 54.0 & 5.4 & 60 & 2.10 & \\
4 & & 49.5 & 4.9 & 55 & 6.99 & \\
5 & & 49.5 & 4.9 & 55 & 0.99 & \\
\hline
\end{tabular}

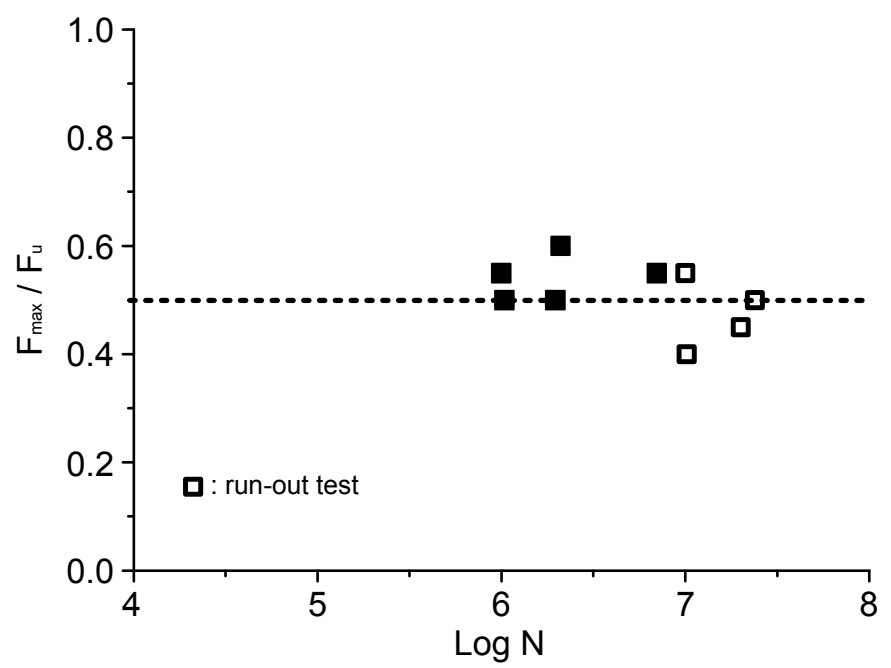

Figure 4. S-N diagram

\subsection{Characteristic behaviour}

All the RU-RC beams showed similar behaviour until failure under bending fatigue. The characteristic behaviour is discussed by looking at the behaviour of Test 2 specimen. First, deformation of RUHPFRC layer is explained; then, the behaviour of the RU-RC beam is mentioned chronologically focusing on failure mechanism.

\subsubsection{Deformation of R-UHPFRC layer}

Distribution and evolution of deformation of $\mathrm{R}$ UHPFRC layer during Test $2-\mathrm{i}$ is displayed in Figure 5. G1 to G7 on the horizontal axis indicate the displacement transducers on the top surface of RUHPFRC layer (Fig. 3). Dashed line in Figure 5 shows calculated deformation and its distribution almost follows acting moment distribution. When compared with the calculated deformation, measured deformation was significantly different from the beginning of the test and that difference became larger as the number of cycles increased. This is explained from the two viewpoints as follows.

1) Variation of material properties Variation of material properties of UHPFRC in the hardening domain may have a signifi- 
cant effect on observed deformation. For a given fatigue stress level, large range of local UHPFRC deformations may be obtained as shown in Figure 6 leading to the large variation in local deformation values as measured by G1 to G7 transducers.

2) Reduction of UHPFRC stiffness

Stiffness of UHPFRC was reduced due to micro- and macrocracking caused by fatigue stress as the number of cycles increased. Therefore, deformation of R-UHPFRC developed gradually under the same acting moment. In the case of Test 2-i, it was observed that several macrocracks intensively developed at G3 zone, which led to reduction of UHPFRC stiffness locally and the deformation of G3 zone thus increased significantly (Fig. 5). Approaching the end of the test, these macrocracks coalesced into one distinct macrocrack (Fig. 7).

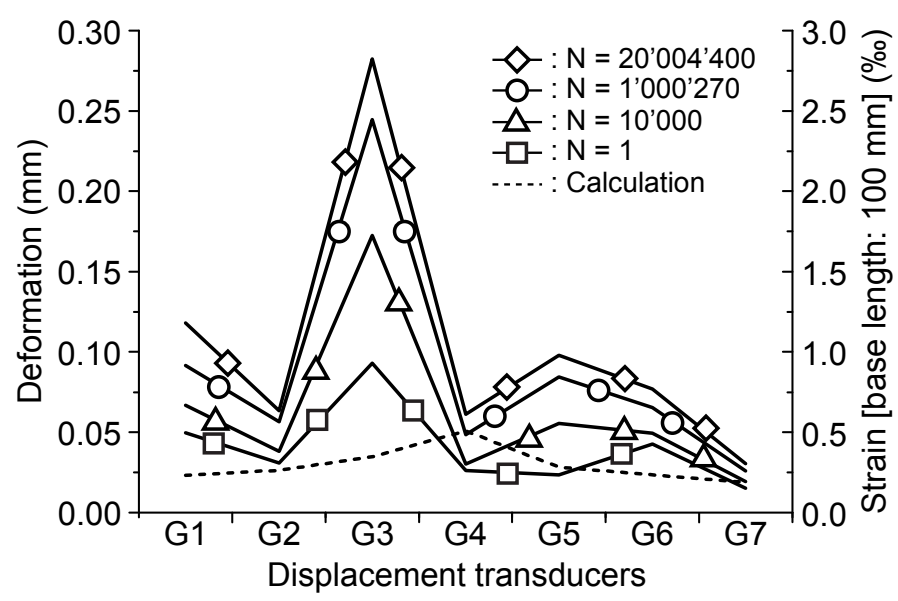

Figure 5. Distribution and evolution of deformation of RUHPFRC layer during Test 2-i

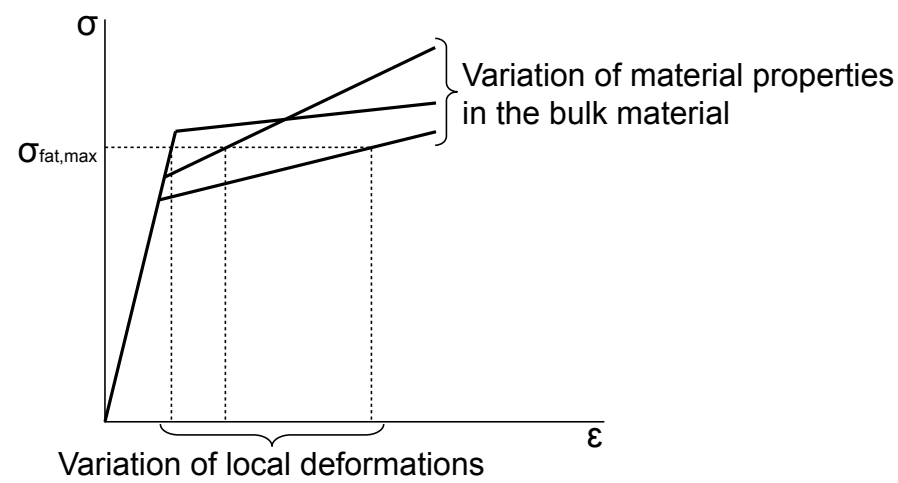

Figure 6. Variation of local deformation of UHPFRC under constant tensile fatigue stress

\subsubsection{Chronological behaviour of $R U-R C$ beam}

i. During the first 10 cycles a few vertical macrocracks developed crossing the interface between R-UHPFRC layer and RC part on the side surface of the specimen (G3 zone, Fig. 7). Tensile stress in top steel rebars of RC part was about $30 \mathrm{MPa}$ corresponding to $0.15 \%$ strain, which caused macrocracking of the concrete. The presence of R-UHPFRC layer cannot prevent but reduce this macrocracking in concrete.

ii. As for the run-out test (Test 2-i), growth rate of deflection and deformation of R-UHPFRC layer became moderate after about 1million cycles (Fig. 8). Further macrocrack development on the top surface of R-UHPFRC layer and the side surface of the specimen didn't occur.

iii. As for the test showing fatigue failure (Test 2-ii), one of the four rebars in R-UHPFRC layer fractured at around 828,000 cycles (1) in Fig. 9b). As a consequence, deformation of R-UHPFRC layer and its growth rate increased and deformation localised in a macrocrack on R-UHPFRC layer. Deflection also increased slightly, but its growth rate was only slightly higher than before (1) in Fig. 9a).

iv. One of the remaining three rebars then fractured at about 1,764,000 cycles. Growth rate of deflection and localised deformation on RUHPFRC layer became significantly large (2) in Fig. 9).

v. After sustaining additional about 168,000 cycles one of the remaining two rebars fractured at about 1,932,000 cycles (3) in Fig. 9); then the final rebar in UHPFRC fractured at about 1,952,000 cycles (4) in Fig. 9). Fracture of the fourth rebar was due to exhausting of resistance rather than due to fatigue.

vi. Since applied maximum fatigue bending moment was almost at the same level as the moment resistance of RC part, the RU-RC beam failed and lost its load bearing capacity soon after the fracture of R-UHPFRC layer.

All the four rebars in R-UHPFRC layer fractured almost at the same cross section causing one fracture plane in the R-UHPFRC layer perpendicular to the longitudinal axis of the RU-RC beam (Fig. 7).

The R-UHPFRC layer, in particular the steel rebars in the layer determine the behaviour of the RU$\mathrm{RC}$ beam under bending fatigue. Stress amplitude in the steel rebars in R-UHPFRC layer is thus the most relevant factor for the fatigue behaviour of the RU- 
RC beam. UHPFRC carries stress and contributes to reduction of the stress in the rebars; however, stress in UHPFRC transfers to the rebars gradually as deformation (crack opening) of UHPFRC increases due to fatigue.
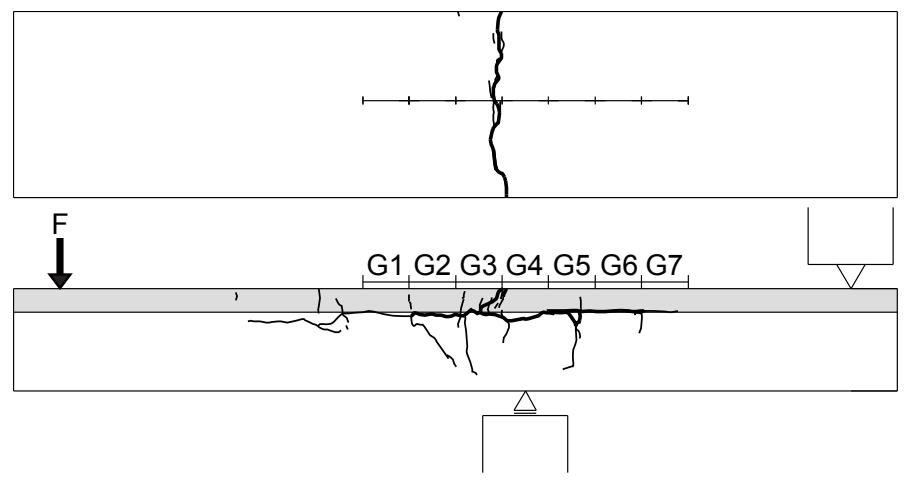

Figure 7. Final crack pattern of Test 2 specimen

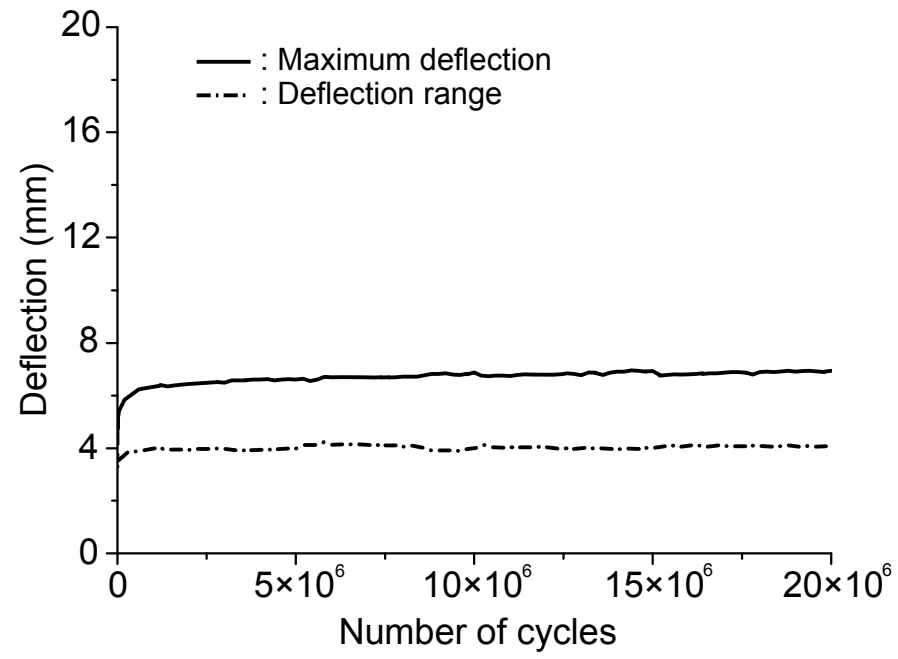

(a)

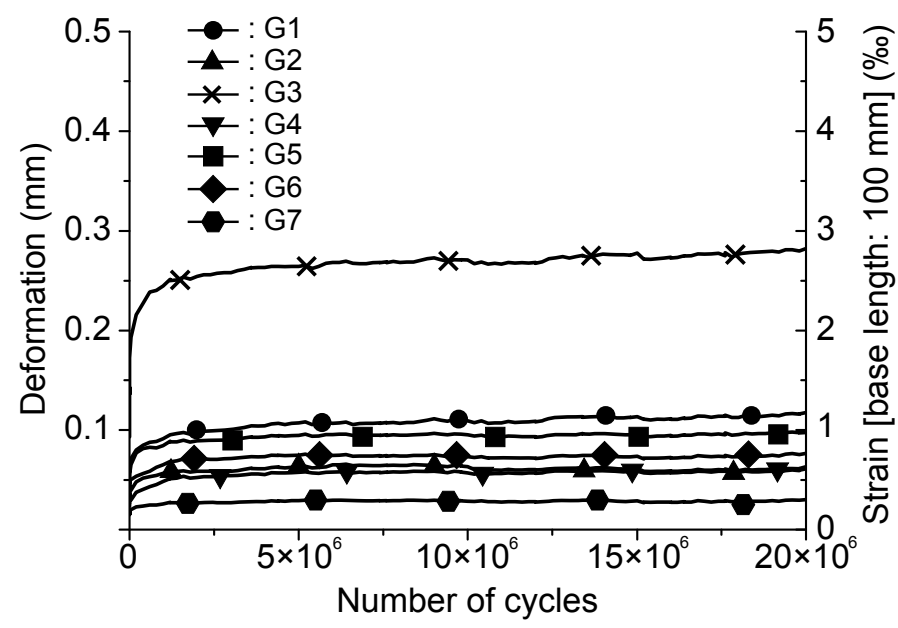

(b)

Figure 8. (a) Deflection and (b) deformation growth curves of Test 2-i showing no fatigue failure after 20 million cycles (runout)

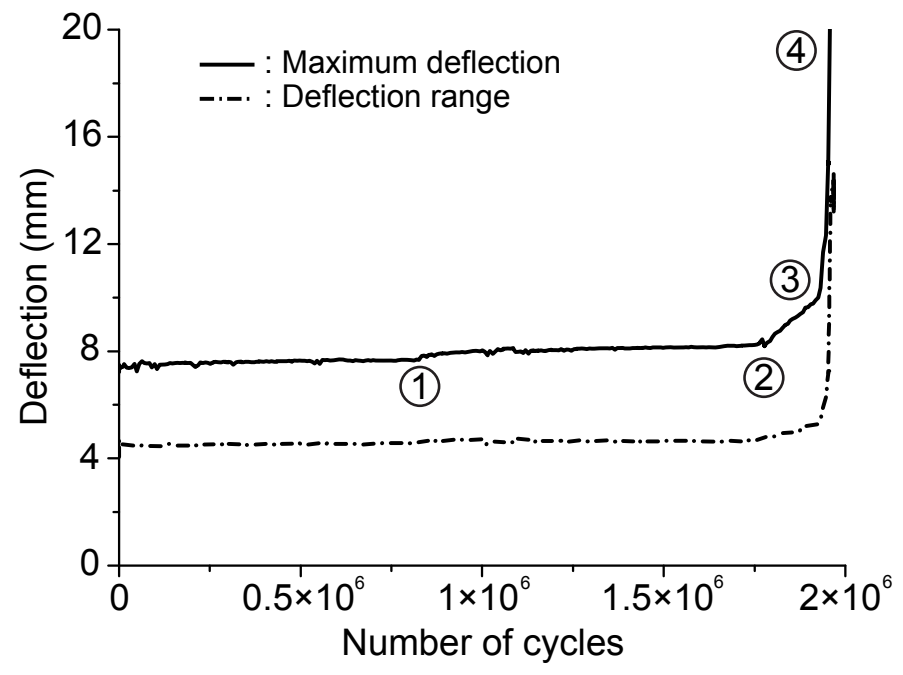

(a)

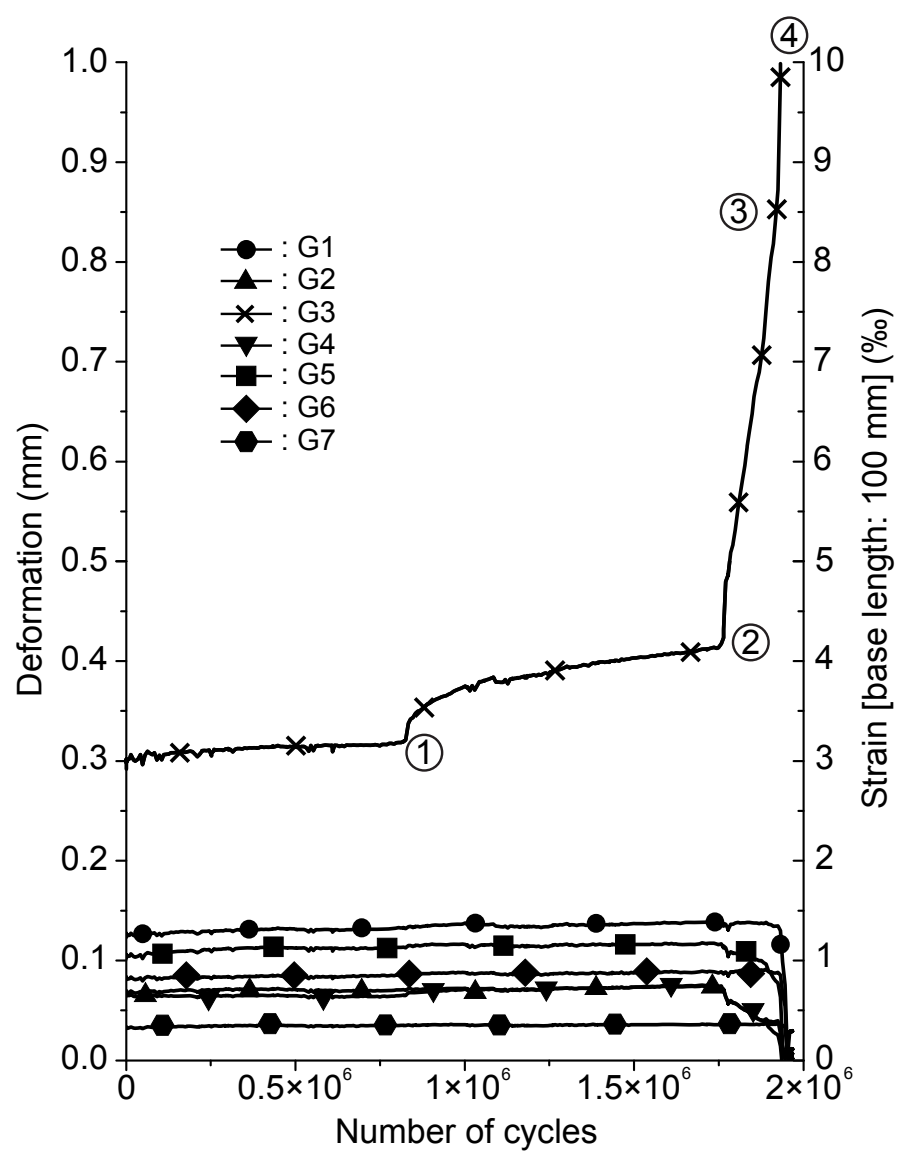

(b)

Figure 9. (a) Deflection and (b) deformation growth curves of Test 2-ii

\section{FATIGUE DEDIGN RULES FOR RU-RC COMPOSITE MEMBERS UNDER BENDING FATIGUE}

On the basis of the present experimental test results, design rules for RU-RC member under bending fatigue are proposed. 
The fatigue safety of a structural member is investigated by checking if the following condition is satisfied:

$\mathrm{n}_{\text {fat }}=\frac{\mathrm{R}_{\mathrm{d}, \text { fat }}}{\mathrm{E}_{\mathrm{d}, \text { fat }}} \geq 1.0$

where $\mathrm{n}_{\text {fat }}=$ fatigue safety index; $\mathrm{R}_{\mathrm{d} \text {,fat }}=$ examination value for the fatigue resistance; $E_{d, \text { fat }}=$ examination value for the fatigue action effect. In the present case of RU-RC members, bending moment is used as examination value. As indicated in section 4.1, the fatigue limit of the RU-RC beam is $50 \%$ of the ultimate static strength. Consequently, RU-RC member needs to be designed to satisfy the following condition:

$\mathrm{n}_{\text {fat }}=\frac{0.5 \times \mathrm{M}_{\mathrm{Rd}}}{\mathrm{M}_{\mathrm{d}, \text { fat }}} \geq 1.0$

where $\mathrm{M}_{\mathrm{Rd}}=$ examination value of moment resistance of the RU-RC member; $\mathrm{M}_{\mathrm{d} \text {,fat }}=$ examination value of maximum acting moment due to fatigue loading.

Since R-UHPFRC layer determines the fatigue behaviour of RU-RC member, the fatigue safety of the R-UHPFRC needs to be verified, which is done separately for both the steel rebars and the UHPFRC.

For the steel rebars, a fatigue safety check with respect to the fatigue limit is performed in a first approximation:

$$
\Delta \sigma_{\text {sd }}\left(Q_{\text {fat }}\right) \leq \Delta \sigma_{\text {sd,D }}
$$

where $\Delta \sigma_{\text {sd }}=$ examination value for stress range due to fatigue; $\mathrm{Q}_{\mathrm{fat}}=$ characteristic value of fatigue loading; $\Delta \sigma_{\mathrm{sd}, \mathrm{D}}=$ examination value for fatigue limit of straight steel rebars. According to the current design codes, $\Delta \sigma_{\mathrm{sd}, \mathrm{D}}=145 \mathrm{MPa}$ for straight steel rebars of diameter smaller than $20 \mathrm{~mm}$.

For UHPFRC under tensile fatigue, the following criteria are proposed for maximum tensile fatigue stress and strain with respect to a fatigue limit check:

$$
\begin{aligned}
& \sigma_{\mathrm{U}, \text { fat } \max } \leq 0.35 \times\left(\mathrm{f}_{\mathrm{Ute}}+\mathrm{f}_{\mathrm{Utu}}\right) \\
& \varepsilon_{\mathrm{U}} \leq 0.8 \times \varepsilon_{\mathrm{Utu}}
\end{aligned}
$$

where $\sigma_{\mathrm{U}, \text { fat,max }}=$ maximum fatigue stress in UHPFRC; $\mathrm{f}_{\mathrm{Ute}}=$ elastic limit strength of UHPFRC; $\mathrm{f}_{\mathrm{Utu}}=$ tensile strength of UHPFRC; $\varepsilon_{U}=$ strain in the UHPFRC due to fatigue and eventual restrained conditions in the RU-RC composite system; $\varepsilon_{\mathrm{Utu}}=$ strain of UHPFRC corresponding to tensile strength of UHPFRC.

\section{APPLICATION}

UHPFRC and R-UHPFRC have been applied to concrete structures such as road bridges and buildings for improvement of load bearing capacity and durability (Brühwiler 2009, Brühwiler \& Denarié 2008, Denarié \& Brühwiler 2006). A case of practical application of UHPFRC is described in this section.

Massive RC slab bridge built in 1963 with six supporting columns was improved by applying UHPFRC and R-UHPFRC to its whole deck surface including the sidewalks in autumn 2011. The bridge located near Lausanne, Switzerland, is part of a road with heavy traffic (Fig. 10). Load bearing capacity of the bridge was found to be insufficient for today's and future vehicles. Besides, its deck slab was deteriorated due to chloride induced corrosion of steel rebars. UHPFRC layer of $25 \mathrm{~mm}$ thickness was designed for strengthening and waterproofing the deck except the area above columns where $65 \mathrm{~mm}$-thick UHPFRC layer with steel rebars of 18 and $22 \mathrm{~mm}$ diameter was designed for improving bending and punching shear resistance (Fig. 12).

The UHPFRC mix contained cement, limestone filler, silica fume, quartz sand, $4.5 \%$ steel fibres by volume and superplasticiser. Limestone filler was used because it leads to a more economic, workable and environmentally friendly UHPFRC (Denarié et al. 2011). The UHPFRC material was prepared on site and about 300 litres were mixed per batch.

$\mathrm{RC}$ top surface of 20 to $40 \mathrm{~mm}$ depth was first treated with high pressure water jet. UHPFRC was then cast with standard and simple tools (Fig. 11). Bituminous pavement was finally applied on a bituminous emulsion on the UHPFRC surface after more than three days of curing. Traffic in both directions was kept in service on one traffic lane during the works.

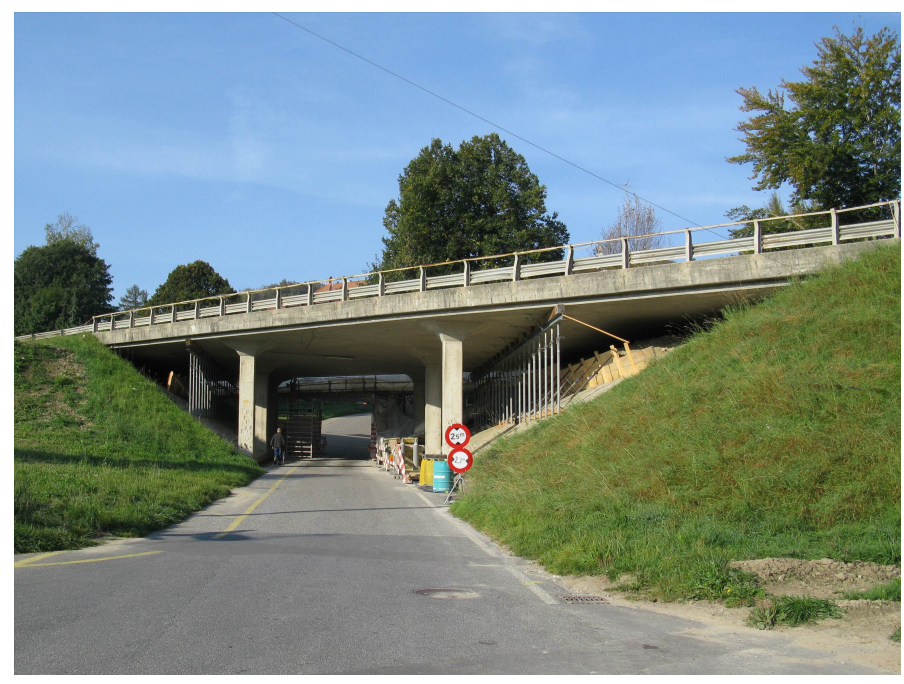

Figure 10. RC slab bridge improved with UHPFRC 


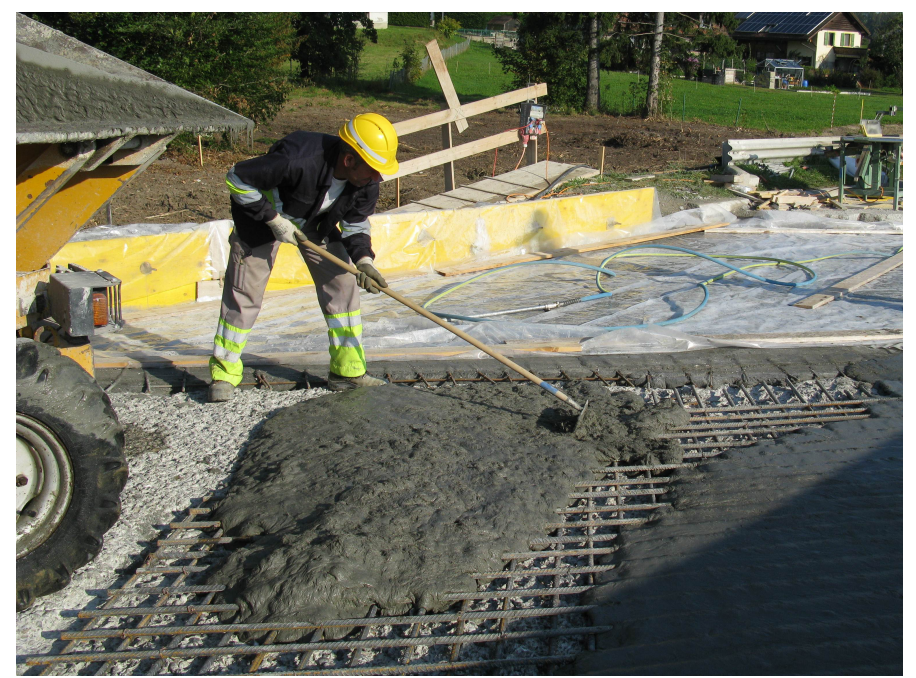

Figure 11. Handling of UHPFRC with simple tool

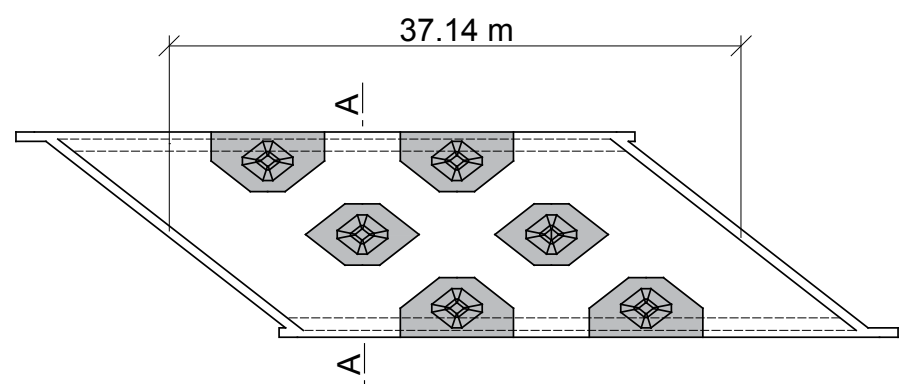

(a)

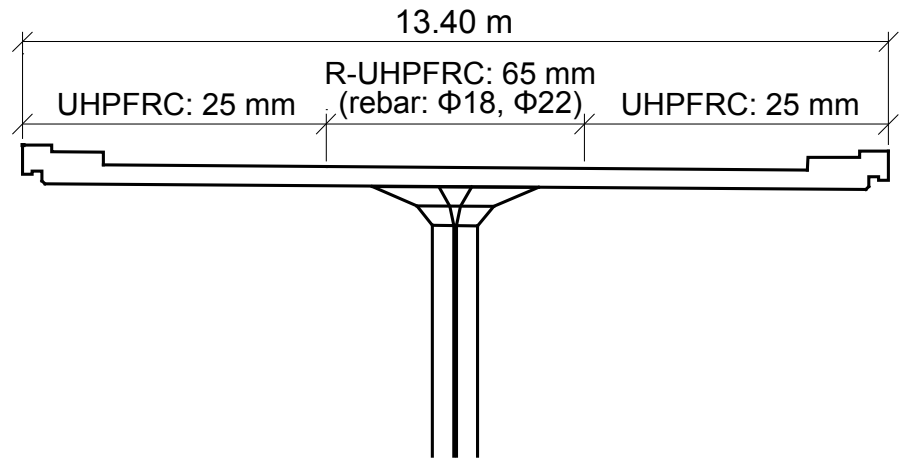

(b)

Figure 12. (a) Plan and (b) cross section at A-A of the RC slab bridge

\section{CONCLUSION}

The following conclusions are obtained from the bending fatigue tests of RU-RC beams.

1) S-N diagram was obtained from bending fatigue tests on RU-RC beams. Although some scatter was observed in the test results, fatigue limit at 10 million cycles was estimated to be at a solicitation level of about $50 \%$ of the ultimate static strength of the RU-RC beam.

2) All the RU-RC beams showed similar behaviour until fatigue failure. Differences in deformation of R-UHPFRC layer between calculation and measurement is explained to be due the variation of UHPFRC material properties. Growth of the deformation of RUHPFRC was attributed to stiffness degradation of UHPFRC caused by microcracking in the hardening domain.

3) Fatigue fracture process of RU-RC beams was determined by fatigue fracture of steel rebars in the R-UHPFRC layer. Fatigue stress amplitude in steel rebars in the $\mathrm{R}$ UHPFRC layer is thus the most relevant parameter for the fatigue resistance of the RU$\mathrm{RC}$ beam.

4) Fatigue design rules for RU-RC members under bending fatigue were proposed for fatigue safety check with respect to the fatigue limit. Fatigue safety needs to be checked for RU-RC member as well as for steel rebars and UHPFRC fatigue resistances.

\section{REFERENCES}

Brühwiler E. 2009. Rehabilitation of bridges using Ultra-High Performance Fibre Reinforced Concrete. Proceedings of 5th New York City Bridge Conference, August 17-18 2009.

Brühwiler E. \& Denarié E. 2008. Rehabilitation of concrete Structures using Ultra-High Performance Fibre Reinforced Concrete. Proceedings of UHPC-2008: the Second International Symposium on Ultra High Performance Concrete. Kassel, Germany: 895-902.

Denarié E. \& Brühwiler E. 2006. Structural rehabilitations with Ultra High Performance Fibre Reinforced Concretes. International Journal for Restoration of Buildings and Monuments Vol. 12 No. 5 and 6: 453-465.

Denarié E., Kazemi-Kamyab H., Brühwiler E., Haddad B. \& Nendaz S. 2011. Béton fibré ultra performant pour la maintenance, un nouvel élan. Tracés No. 12 June 2011: 20-23.

Wuest J. 2007. Structural behaviour in tension of Ultra-High Performance Fiber Reinforced Concrete in composite elements. Doctoral thesis No. 3987. Ecole Polytechnique Fédérale de Lausanne (EPFL). (in French). 